\title{
Salinity effects on survival and life history of two freshwater cladocerans (Daphnia magna and Daphnia longispina)
}

\author{
A.M.M. Gonçalves ${ }^{1,2 *}$, B.B. Castro ${ }^{1}$, M. A. Pardal ${ }^{2}$, F. Gonçalves ${ }^{1}$ \\ ${ }^{1}$ Departamento de Biologia da Universidade de Aveiro \& Centro de Estudos do Ambiente e do Mar (CESAM), Campus Universitário de
Santiago, 3810-193 Aveiro, Portugal
${ }^{2}$ IMAR, Departamento de Zoologia, Universidade de Coimbra, 3004-517 Coimbra, Portugal
}

Salinity is a serious threat to freshwater ecosystems, particularly those near coastal areas. An increase in salinity produces drastic changes in community structure of freshwaters, sometimes in an irreversible fashion. Thus, freshwater species must cope with salinity stress in a manner proportional to their degree of tolerance. Bearing this in mind, we studied the acute and chronic effects of different salinity concentrations in two species of cladocerans: Daphnia magna Straus, a standard test organism, and Daphnia longispina O. F. Müller, an autochthonous species. Salinity experiments were based on successive dilutions of a stock solution of $\mathrm{NaCl}$ in a synthetic medium. The results showed that $D$. magna is more tolerant than $D$. longispina, both in acute $\left(\mathrm{EC}_{50} 5.9\right.$ and $2.9 \mathrm{~g} / \mathrm{L}$, respectively) and chronic $\left(\mathrm{EC}_{50} 5.0\right.$ and $2.2 \mathrm{~g} / \mathrm{L}$, correspondingly) exposures. In the chronic exposure, salinity caused a significant reduction in fecundity and a developmental delay (increase in age at first reproduction), as well as a decrease in the growth rate of daphnids. However, these effects were mainly observed at salinity concentrations where mortality occurred.

Keywords: saline stress, sodium chloride, toxicity tests, freshwater zooplankton, life history.

\section{Introduction}

Salinity intrusion in freshwater ecosystems is a problem that is becoming increasingly serious due to environmental change. These systems can suffer important alterations with the increase of salinity due to global climate change, such as the action of rainwater and wind, evaporation and sea level rise (Schallenberg et al. 2003). This is particularly important in coastal freshwater systems or in estuaries, which occupy a large area in our country (Portugal). Several authors (e.g., Hall \& Burns 2003, Schallenberg et al. 2003) have reported a reduction in the diversity and abundance of zooplankton communities exposed to salinity increases. Freshwater species must either adapt or avoid the saline stress in order to survive and reproduce. The ability of the organisms to survive and reproduce in such unstable environments is as high as their tolerance (Rokneddine \& Chentoufi 2004). Studies have been carried out in freshwater ecosystems threatened by salinity, in order to evaluate how the raise in salinity affects zooplankton, altering ecosystem structure and function (Hall \& Burns 2003, Nielsen et al.

\footnotetext{
*Corresponding author : E-mail : ana.goncalves@bio.ua.pt
}

2003, Schallenberg et al. 2003, Rokneddine \& Chentoufi 2004). Still, there is little information on how the increase of salinity affects ecosystem integrity in order to predict the impact and rehabilitate aquatic systems (Nielsen et al. 2003). Therefore, it is important to study the effect of salinity stress in freshwater organisms. Among these, zooplankton has long been used as a suitable group to assess the impact of environmental change, in part due to its key intermediate position in the trophic food web. Zooplanktonic organisms are frequently used as indicators of water quality due to the close relationship between environmental factors and species composition, which are mainly affected by mineralization gradients (Sánchez-Colomer 1996, Boronat et al. 2001). Salinity changes in freshwater systems may greatly affect survival and life history (growth and reproduction) of zooplankters and, consequently, have an impact on higher trophic levels. Cladocerans, one of the most abundant primary consumer groups in lentic ecosystems, show different physiological tolerances to several ionic components (Bos et al. 1996) and are good indicators of environmental changes (e.g., water quality and/or historical differences), especially regarding salinity changes (Sánchez-Colomer 1996, Boronat et al. 2001, Amsinck et al. 2003). The genus Daph- 
nia, in particular, is more or less tolerant to salinity and the differences among species can produce distinct effects in the system dynamics, such as in the abundance of primary producers, the rate of primary production and rates of nutrient cycling (Boronat et al. 2001, Hairston et al. 2005). As an example, euryhaline Daphnia magna lives in fresh, brackish and athalassohaline waters, while daphnids from the longispina group $(D$. longispina, D. galeata, D. cucullata) prefer waters with low mineralization and are very sensitive to magnesium, for example (e.g., concentrations above $0.6 \mathrm{~g} . \mathrm{L}^{-1}$ become lethal for them) (Alonso 1996).

In order to assess the tolerance of Daphnia to salinity (as $\mathrm{NaCl}$ ), we tested its effects on immobilisation (acute toxicity) and life history (chronic toxicity) responses of two Daphnia species: Daphnia magna Straus and Daphnia longispina O. F. Müller. The former is a common test organism, widely used in standard ecotoxicological procedures, while $D$. longispina is an ubiquitous European species (D. longispina corresponds to $D$. hyalina and $D$. rosea morphotypes, as suggested by Petrusek et al. 2005). The main aims of this study were: 1) to determine salinity thresholds which cause adverse effects to Daphnia spp., both in acute and chronic exposures; 2) to compare these thresholds between species (i.e., to compare their tolerance).

\section{Materials and methods}

\section{Daphnid cultures}

Monoclonal cultures of Daphnia magna (clone A, sensu Baird et al. 1989a) and Daphnia longispina (clone EM7, sensu Antunes et al. 2003) have been reared in our laboratory for several generations using widespread procedures for D. magna (see Baird et al. 1989b, Soares et al. 1992, ASTM 1997). Daphnids were cultured in American Society for Testing and Materials hard water medium (ASTM 1980), to which an organic additive (Ascophyllum nodosum extract, Baird et al. 1989b) was added. Cultures were reared under a $16 \mathrm{~h}^{\mathrm{L}}: 8 \mathrm{~h}^{\mathrm{D}}$ photoperiod (provided by cool fluorescent white lights) and a temperature of $20 \pm 2^{\circ} \mathrm{C}$. The medium was renewed every other day, to a total of three times per week. Animals were fed with Pseudokirchneriella subcapitata (Korshikov) Hindak every other day, at a concentration of $3.0 \times 10^{5}$ cells. $\mathrm{mL}^{-1}$ for D. magna and $1.5 \times 10^{5}$ cells. $\mathrm{mL}^{-1}$ for D. longispina. Algal (food) ration was determined spectrophotometrically, as described for Chlorella vulgaris Beijerinck by Carvalho et al. (1995).

\section{Acute tests}

Tests were performed according to standard protocols (ISO 1996; OECD 2000; EPA 2002) under the same temperature and photoperiod regimes as described for rearing procedures. For both Daphnia species, experiments were initiated with neonates $(<24$-h-old) obtained from the same bulk culture, born between the $3^{\text {rd }}$ and $5^{\text {th }}$ broods. The experimental saline concentrations were obtained by successive dilutions of a stock solution of sodium chloride $(\mathrm{NaCl})$ in the synthetic hard water medium, with salinity concentrations ranging from $4.40 \mathrm{~g} . \mathrm{L}^{-1}$ to $7.09 \mathrm{~g} . \mathrm{L}^{-1}$ and from $2.50 \mathrm{~g} . \mathrm{L}^{-1}$ to 4.03 g.L.- for D. magna and D. longispina, correspondingly. The culture medium was used as the control treatment. Tests were carried out in glass beakers (four per treatment) containing $100 \mathrm{~mL}$ of test solutions. A static design was employed, using 20 animals (randomly divided into four groups of five animals) per control and per $\mathrm{NaCl}$ concentration. Daphnids were exposed to the different salinity concentrations during 48 h without food or organic extract. Vessels were checked for immobilised individuals, at 24 and $48 \mathrm{~h}$, for posterior determination of $\mathrm{EC}_{50}$ values (see Statistical analyses).

\section{Chronic tests}

Tests were conducted for 21 days according to standard protocols (ASTM 1997; OECD 1998; ISO 2000), under the same temperature and photoperiod regimes as described for rearing procedures. Tests were initiated with neonates $(<24$-h-old) obtained from the same bulk culture, born between the $3^{\text {rd }}$ and $5^{\text {th }}$ broods. The body lengths (from the base of the spine to the top of the head) of a subsample $(n=20)$ of neonates from the same batch were measured under stereoscope magnification in order to determine their size at the beginning of the test ( $l_{i}-$ initial body length). The saline concentrations tested ranged from $3.42 \mathrm{~g} . \mathrm{L}^{-1}$ to $5.50 \mathrm{~g} . \mathrm{L}^{-1}$ for D. magna and from $1.55 \mathrm{~g} . \mathrm{L}^{-1}$ to $2.50 \mathrm{~g} . \mathrm{L}^{-1}$ for $D$. longispina. The culture medium was used as the control treatment. Experiments were carried out using glass beakers (10 per treatment) containing $50 \mathrm{~mL}$ of test solutions (including organic extract, unlike in the acute tests). A semi-static design was employed, using 10 individualised organisms (i.e. one per replicate) randomly assigned to the control and to each $\mathrm{NaCl}$ concentration. Daphnids were fed daily (with $P$. subcapitata) and transferred to freshly-prepared test solutions every other day. Animals were checked every day at the same approximate hour for mortality and reproductive state (presence of eggs or offspring). When neonates were released, they were counted and discar- 
ded. A life history table was built with the mortality and fecundity data. At the end of the test, all surviving organisms (mothers) were measured (from the base of the spine to the top of the head) under stereoscope magnification $\left(l_{f}-\right.$ final body length). This allowed the calculation of the somatic growth rate, which was estimated from the initial $\left(l_{i}\right.$, in $\left.\mathrm{mm}\right)$ and final $\left(l_{f}\right.$, in $\left.\mathrm{mm}\right)$ body size of the daphnids, according to the following expression:

$$
\text { growth rate }=\frac{\ln \left(l_{f}\right)-\ln \left(l_{i}\right)}{\Delta t},
$$

where growth rate is expressed in day $^{-1}$ and $\Delta \mathrm{t}$ is the time interval (21 days).

Survival and fecundity estimates were also used to compute the intrinsic rate of population increase $(r)$. This demographic parameter was iterated from the Euler-Lotka equation:

$$
1=\sum_{x=0}^{n} e^{-r x} l_{x} m_{x}
$$

where $r$ is expressed in day ${ }^{-1}, x$ is the age class $(1 \ldots \mathrm{n}$ days), $l_{x}$ is the probability of surviving to age $x$, and $m_{x}$ is the fecundity at age $x$. Pseudovalues and standard errors for $r$ were estimated using the jack-knifing technique described by Meyer et al. (1986).

\section{Statistical analysis}

For each Daphnia species, the $\mathrm{EC}_{50}$ values for immobilisation (acute tests) and fecundity (chronic tests) were calculated by probit analysis (Finney 1971). To test the significance of the effect of salinity on the life history parameters of the daphnids, a one-way ANOVA was employed on the chronic test data. When the ANOVAs were statistically significant, a Dunnett test was then applied to the data in order to determine which concentrations were significantly different from the control group. This procedure allowed the determination of the standard NOEC (No Observed Effect Concentration) and LOEC (Lowest Observed Effect Concentration) values. A significance level $(\alpha)$ of 0.05 was used in all the analyses.

\section{Results}

Acute immobilisation tests showed that D. magna was more tolerant to salinity than $D$. longispina. The acute $\mathrm{EC}_{50}$ value determined for D. magna $\left(5.9\right.$ g. $\left.\mathrm{L}^{-1}\right)$ was about twice the value obtained for $D$. longispina $\left(2.9\right.$ g.. - $\left.^{-1}\right)$ (Table 1$)$. In absolute terms, the $\mathrm{NaCl}$ concentrations used in the acute test represent low levels of salinity.

Table 1. Acute (immobilisation and chronic (fecundity) $\mathrm{EC}_{50}$ values of salinity (as $\mathrm{NaCl}$ ) for $D$. magna and D. longispina, with respective $95 \%$ confidence limits (in brackets).

\begin{tabular}{ccc}
\hline Species & Acute $\mathrm{EC}_{50}$ & $\begin{array}{c}\text { Chronic } \\
\mathrm{EC}_{50}\end{array}$ \\
\hline \multirow{2}{*}{ D. magna } & $\mathbf{5 . 9} \mathbf{g} \cdot \mathrm{L}^{-1}$ & $\mathbf{5 . 0} \mathbf{g} \cdot \mathrm{L}^{-1}$ \\
& $(5.5-6.5)$ & $(4.9-5.1)$ \\
D. longispina & $\mathbf{2 . 9} \mathbf{g} \cdot \mathrm{L}^{-1}$ & $\mathbf{2 . 2} \mathbf{g} \cdot \mathrm{L}^{-1}$ \\
& $(2.8-3.0)$ & $(2.2-2.3)$ \\
\hline
\end{tabular}

Salinity caused a significant effect on the life history of both daphnids, affecting all parameters, with the exception of number of broods in D. magna (Table 2). Figures 1 and 2 show the life history responses of $D$. magna and $D$. longispina to salinity, respectively. Mortality was not higher than $10 \%$ in D. magna, except in the last concentration where it achieved the highest value $(90 \%)$. In D. longispina, mortality increased in the last two concentrations (30 and $90 \%$, correspondingly). A concentration-dependent decrease in the number of offspring was observed for both species, accompanied by a developmental delay, i.e. an increase in age at first reproduction (AFR). The number of broods produced per female was significantly reduced only in $D$. longispina. As a consequence of the lower fecundity and of the developmental delay, the intrinsic rate of increase $(r)$ was also significantly reduced in both species in a concentration-dependent manner. A decrease in the somatic growth rate of both species was also ob-

Table 2. Summary of one-way ANOVAs applied to the life history parameters with $D$. magna and D. longispina (d.f. - degrees of freedom; $\mathrm{p}$ - probability; NS - non significant).

\begin{tabular}{ccccccc}
\hline Parameters & \multicolumn{3}{c}{ D. magna } & \multicolumn{3}{c}{ D. longispina } \\
& F & d.f. & p & F & d.f. & p \\
\hline Number of offspring & 4.1 & 5,48 & 0.004 & 49 & 5,46 & $<0.001$ \\
Age at first reproduction & 5.5 & 6,55 & $<0.001$ & 34 & 5,49 & $<0.001$ \\
Number of broods & 2.3 & 5,50 & NS & 29 & 5,46 & $<0.001$ \\
Somatic growth rate & 4.3 & 5,48 & 0.003 & 15 & 5,46 & $<0.001$ \\
Intrinsic rate of increase & 24 & 6,62 & $<0.001$ & 39 & 5,53 & $<0.001$ \\
\hline
\end{tabular}



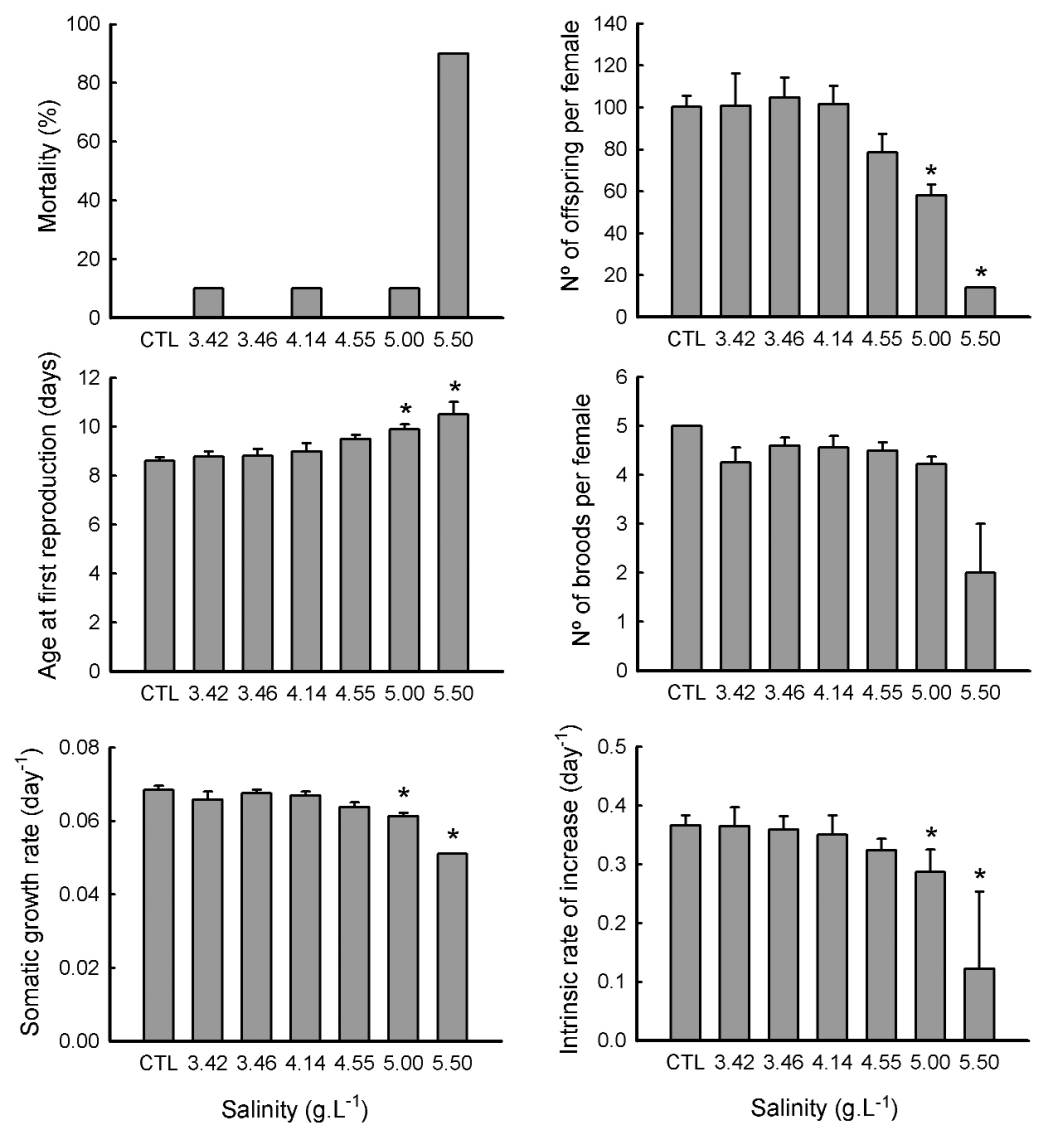

Fig. 1. Life history parameters of Daphnia magna exposed to different salinities (as $\mathrm{NaCl}$ concentrations) for 21 days. Error bars represent standard error and $*$ indicates statistically significant differences (Dunnett test, $\mathrm{p} \leq 0.05$ ) between the test concentrations and the control (CTL).

served; however, in D. longispina, this reduction was preceded by a stimulatory effect at low levels $(1.55$ g. $\left.\mathrm{L}^{-1}\right)$. The number of offspring was the most affected parameter, being drastically reduced with the increase of salinity in both species.

The $\mathrm{EC}_{50}$ values determined from the fecundity data showed again that D. magna tolerate salinity concentrations two-fold higher than the salinity concentrations tolerated by $D$. longispina (Table 1 ). Indeed, the LOEC value for all parameters in D. magna was 5 g. $\mathrm{L}^{-1}$, while for $D$. longispina it ranged between 1.71

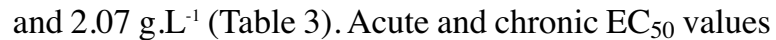
were very close within each species, for both Daphnia species (Table 1). In fact, the concentrations used in the chronic test were very close to the acute $\mathrm{EC}_{50}$ value for each species, with life history impairment occurring immediately prior to high mortality (see Figs 1 and 2).
For both Daphnia species, reproductive impairment and mortality occurred within a narrow range of salinities (5.00-5.50 g.L $\mathrm{L}^{-1}$ in D. magna and 1.71-2.50 g.L. ${ }^{-1}$ in D. longispina).

\section{Discussion}

This study demonstrated that relatively low levels of salinity are deleterious to both freshwater cladoceran species: D. magna and D. longispina. The acute and chronic $\mathrm{EC}_{50}$ values for D. magna $\left(5.9 \mathrm{~g} . \mathrm{L}^{-1}\right.$ and 5.0 g. $\mathrm{L}^{-1}$, respectively) were about two-fold the values obtained for D. longispina (2.9 g... $\mathrm{L}^{-1}$ and $2.2 \mathrm{~g} . \mathrm{L}^{-1}$, correspondingly), which confirmed that $D$. longispina is more sensitive to salinity stress. The higher sensitivity of $D$. longispina, relatively to $D$. magna, has also been shown for other stressors, namely xenobiotics (e.g. Antunes et al. 2004; Marques et al. 2004a,b), although this 

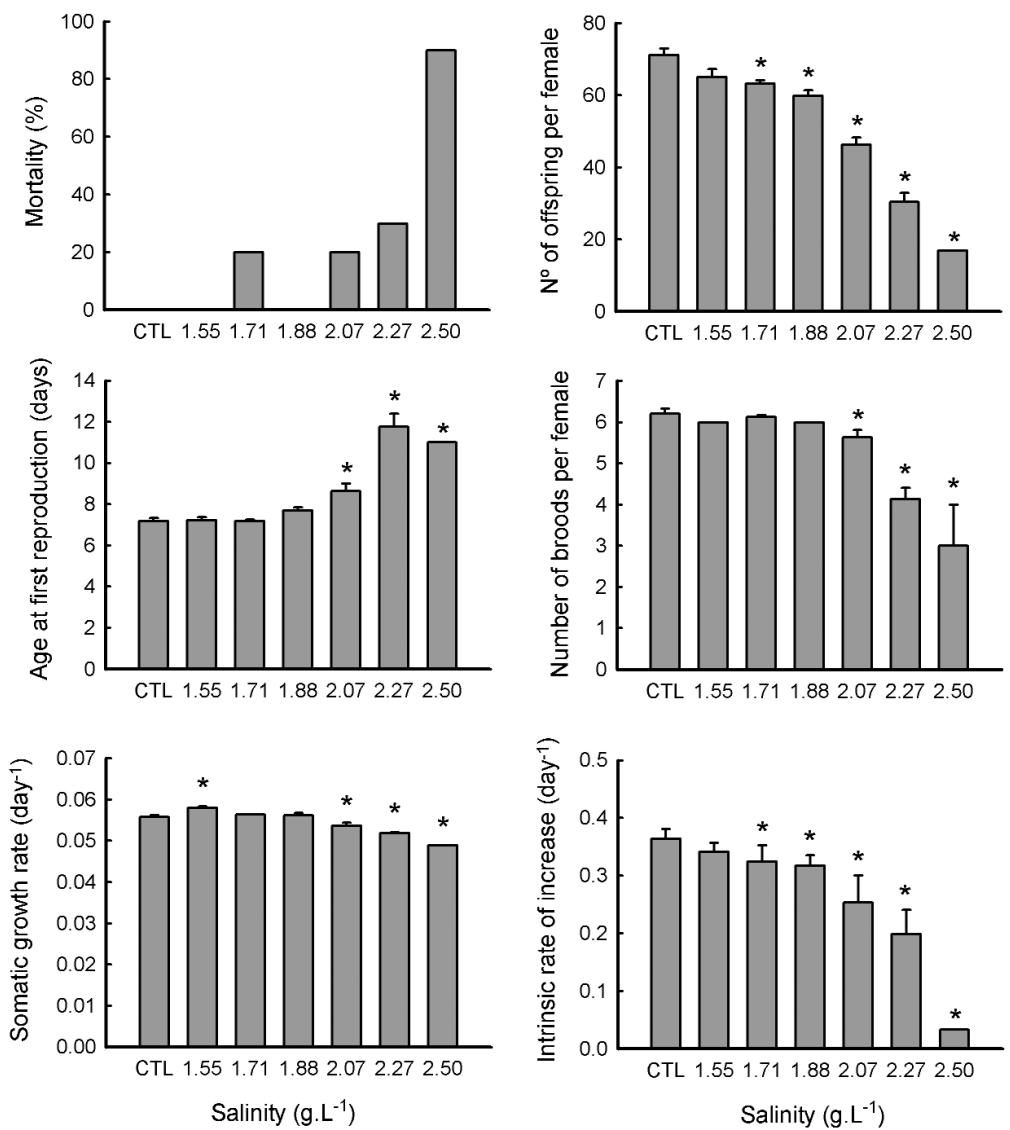

Fig. 2. Life history parameters of Daphnia longispina exposed to different salinities (as $\mathrm{NaCl}$ concentrations) for 21 days. Error bars represent standard error and * indicates statistically significant differences (Dunnett test, $\mathrm{p} \leq 0.05$ ) between the test concentrations and the control (CTL).

Table 3. NOEC and LOEC values (in $\mathrm{g} . \mathrm{L}^{-1}$ ) for each life history parameter of $D$. magna and $D$. longispina exposed to different salinity concentrations during 21 days.

\begin{tabular}{ccccc}
\hline \multirow{2}{*}{ Parameters } & \multicolumn{2}{c}{ D. magna } & \multicolumn{2}{c}{ D. longispina } \\
& NOEC & LOEC & NOEC & LOEC \\
\hline Number of offspring & 4.55 & 5 & 1.55 & 1.71 \\
Age at first reproduction & 4.55 & 5 & 1.88 & 2.07 \\
Number of broods & - & - & 1.88 & 2.07 \\
Somatic growth rate & 4.55 & 5 & 1.88 & 2.07 \\
Intrinsic rate of increase & 4.55 & 5 & 1.55 & 1.71 \\
\hline
\end{tabular}

is not always the case (see e.g. Pereira et al. in press). This poses questions on the validity of standard test organisms (particularly D. magna) as representative of related taxa.

The $\mathrm{EC}_{50}$ values obtained in this work are comparable to other studies with Daphniidae (see Table 4). A high variability of protocols has been used when testing the effects of salinity, so comparisons must be made with caution. Kefford et al. (2004), for example, stated that artificial sea salt is less toxic than $\mathrm{NaCl}$. Differences in tolerance to artificial sea salt and $\mathrm{NaCl}$ may be due to $\mathrm{pH}$, which tends to be lower in $\mathrm{NaCl}$ treat- 
Table 4. Acute and chronic $\mathrm{EC}_{50}$ values of salinity calculated by this study and other authors for Daphniidae.

\begin{tabular}{|c|c|c|c|}
\hline Species & Acute $\mathrm{EC}_{50}$ & Chronic $\mathrm{EC}_{50}$ & Reference \\
\hline D. longispina & $2.9 \mathrm{~g} \cdot \mathrm{L}^{-1}$ & $2.2 \mathrm{~g} \cdot \mathrm{L}^{-1}$ & This study \\
\hline D. magna & $8.3 \mathrm{~g} \cdot \mathrm{L}^{-1}$ & - & Cowgill and Milazzo (1996) \\
\hline D. magna & $11.3 \mathrm{~g} \cdot \mathrm{L}^{-1}$ & $8.57 \mathrm{~g} \cdot \mathrm{L}^{-1}$ & Schuytema et al. (1997) \\
\hline D. magna & $0.49 \mathrm{~g} \cdot \mathrm{L}^{-1}$ & - & Semsari and Haït-Amar (2001) \\
\hline D. magna & $7.3 \mathrm{~g} \cdot \mathrm{L}^{-1}$ & - & Do Hong et al. (2004) \\
\hline D. magna & $5.9 \mathrm{~g} \cdot \mathrm{L}^{-1}$ & $5.0 \mathrm{~g} \cdot \mathrm{L}^{-1}$ & This study \\
\hline D. carinata & $\begin{array}{l}7.7 \mathrm{~g} \cdot \mathrm{L}^{-1}(\text { artificial } \\
\left.\text { sea water }-25^{\circ} \mathrm{C}\right)\end{array}$ & - & Kefford (2000) \\
\hline D. carinata & $\begin{array}{c}5.3 \mathrm{~g} \cdot \mathrm{L}^{-1}(\text { saline } \\
\left.\text { lake water }-25^{\circ} \mathrm{C}\right)\end{array}$ & - & Kefford (2000) \\
\hline D. carinata & $0.9 \mathrm{~g} \cdot \mathrm{L}^{-1}\left(20^{\circ} \mathrm{C}\right)$ & - & Hall and Burns (2002) \\
\hline $\begin{array}{l}\text { D. carinata } \\
\text { (adults) }\end{array}$ & $\begin{array}{l}2.2 \mathrm{~g} \cdot \mathrm{L}^{-1}\left(10^{\circ} \mathrm{C}\right) \\
1.7 \mathrm{~g} \cdot \mathrm{L}^{-1}\left(20^{\circ} \mathrm{C}\right)\end{array}$ & - & Hall and Burns (2002) \\
\hline $\begin{array}{l}\text { D. thomsoni } \\
\text { (7 clones) }\end{array}$ & $7.5-8.8 \mathrm{~g} \cdot \mathrm{L}^{-1}$ & - & Barry et al. (2005) \\
\hline C. cornuta & $2.6 \mathrm{~g} \cdot \mathrm{L}^{-1}$ & - & Do Hong et al. (2004) \\
\hline
\end{tabular}

ments (Kefford et al. 2004). The juvenile $D$. carinata acute $\mathrm{EC}_{50}$ value obtained by Hall \& Burns (2002) was much lower than that obtained by Kefford (2000) (Table 4). Barry et al. (2005) established that salinities of about $4 \mathrm{~g} . \mathrm{L}^{-1}$ were tolerated by some species within the genus Daphnia, showing $48 \mathrm{~h} \mathrm{EC}_{50}$ s for seven $D$. thomsoni clones that were between 7.49 and 8.79 g.L. $\mathrm{L}^{-1}$ (Table 4). The lowest $48 \mathrm{~h} \mathrm{EC} 50$ value $\left(0.49 \mathrm{~g} . \mathrm{L}^{-1}\right)$ in the literature was obtained by Semsari \& Haït-Amar (2001) for D. magna, which is an unusual value when compared to those obtained in this work and in the works described above (Table 4).

Boronat et al. (2001) demonstrated that cladoceran species have different halotolerances, ranging from fresh to saline water bodies, with $D$. longispina being estenohaline (range 0.5-1.2 g.L $\mathrm{L}^{-1}$ ) and D. magna euryhaline (range 3.8-38 g...-1). In fact, D. magna is one of the most halotolerant Daphnia species (Cowgill \& Milazzo 1990, Rokneddine \& Chentoufi 2004, Do Hong et al. 2004, Hairston et al. 2005). Tackx et al. (2004) observed that cladocerans were mostly present in the freshwater part $(<0.7$ p.s.u. - practical salinity units for ocean seawater: 35 p.s.u. $\left.=35 \mathrm{~g} . \mathrm{Kg}^{-1}\right)$ of the Schelde estuary where a horizontal salinity gradient $(0-10$ p.s.u.) is present. On the other hand, other small zooplankters (e.g., rotifers and copepods) were abundant in the brackish water zone (0.7-10 p.s.u.) of the estuary, in the study. Schallenberg et al. (2003) stated that, at salinities above 2.7 p.s.u., the zooplankton community changes from one consisting of copepods, rotifers, cladocerans, amphipods and amoebae at low salinities, to one represented only by rotifers.
Life history parameters can also be affected by the increase of salinity, as shown in our study. In this work, the most drastic reduction caused by $\mathrm{NaCl}$ in life history traits was that observed for the number of neonates. Additionally, growth rate of both daphnid species was also negatively affected and maturation was delayed at the highest concentrations. Similarly, Teschner (1995) concluded that clones of D. magna under brackish conditions grew more slowly and matured on average later than under freshwater conditions. Nevertheless, our results demonstrated that $D$. magna reproduces and lives well at salinity concentrations below $4.55 \mathrm{~g} . \mathrm{L}^{-1}$. These results are comparable to those obtained by Schuytema et al. (1997), who stated that $D$. magna reproduce and survive normally at salinity concentrations below $4 \mathrm{~g} . \mathrm{L}^{-1}$. Both species (D. magna and $D$. longispina) showed higher rate of mortality in the higher concentration, being noticeable a drastic reduction in the number of survivors in this concentration.

Nielsen et al. (2003) stated that microinvertebrates, freshwater algae and aquatic plants appear to be the biological communities less tolerant to increases in salinity, tolerating concentrations below $3 \mathrm{~g} . \mathrm{L}^{-1}$. Other studies (Barron et al. 2002) proved phytoplankton can adapt to salinity conditions, although this process becomes slower as $\mathrm{NaCl}$ concentration increases. Some algae (such as the ones belonging to the genus Dunaliella) are haloterant, growing at high saline media due to physiological adaptations, such as glycerol intracellular accumulation (Avron 1986) and a salt-induced protein (p60) present in the plasma membrane (Fisher 
et al. 1994). Correspondingly, other authors have stated that some cladocerans develop mechanisms to adapt to environmental changes, particularly salinity (Teschner 1995, Schallenberg et al. 2003, Rokneddine \& Chentoufi 2004).

Salinity is an important and crucial factor in determining the presence, dominance and succession of organisms. This work has proved how the increase of $\mathrm{NaCl}$ affects significantly survival and life history traits, which can cause changes in the zooplankton community structure. Other authors (e. g. Nielsen et al. 2003, Bailey et al. 2004) state that, if salinity changes occur very rapidly, organisms can not adapt and freshwater taxa can become locally extinct, transferring dominance to salt tolerant taxa. According to our results, changes in reproduction and growth occur at a range of sodium chloride concentrations very close to lethal levels. As a consequence of this, we hypothesize that salinity will produce a drastic "all-or-nothing" effect in cladoceran assemblages, leading to their extinction, as they are unable to survive or reproduce as soon as their tolerance level is reached. A small increase in salinity seems to be clearly deleterious for indigenous daphnids $(D$. longispina $)$ and it is not surprising that, under saline stress, freshwater systems quickly shift to a more halotolerant assemblage (Nielsen et al. 2003, Bailey et al. 2004). However, Bailey et al. (2004) demonstrated that resistance eggs of Daphnia sp. hatched when returned from high levels of salt to freshwater conditions, suggesting that rapid re-colonization is possible from local ephippial egg banks.

The results obtained in this work suggest that the increase of salinity in freshwater systems can have drastic implications on biodiversity and species composition, affecting the survival, growth and reproduction of species and eliminating them if salinity concentrations remain above their tolerance. Further studies with freshwater species under brackish and saline conditions are required in order to understand how freshwater species adapt to such a stressful environment, in terms of their physiology, and to explain the inter-specific differences in halotolerance. Studies in more realistic and complex scenarios (e.g. mesocosms) may be useful in order to understand the effects of salinity, as well as its interactions with other factors (e.g., nutrients, fish), at the guild/community level, thus providing more ecologically relevant information.

\section{References}

Alonso M. 1996. - Crustacea, Branchiopoda. In Fauna Ibérica - volume 7. Ramos M.A., Tercedor J.A., Ros X.B., Noguera J.G., Sierra A.G., Mayol E.M., Piera F.M., Marino J.S. \& González J.T. (eds). Museo Nacional de Ciencias Naturales, Madrid, 486 p.
Amsinck S. L., Jeppesen E. \& Ryves D. 2003. - Cladoceran stratigraphy in two brackish lakes with special reference to changes in salinity, macrophyte abundance and fish predation. J. Paleolimnol., 29, 495-507.

Antunes S.C., Castro B.B. \& Gonçalves F. 2003. - Chronic responses of different clones of Daphnia longispina (field and ephippia) to different food levels. Acta Oecol., 24, S325-S332.

Antunes S.C., Castro B.B. \& Gonçalves F. 2004 - Effect of food level on the acute and chronic responses of daphnids to lindane. Environ. Pollut., 127, 367-375.

ASTM, 1997. - Standard guide for conducting Daphnia magna lifecycle toxicity tests. Report E 1193-97. American Society for Testing and Materials, Philadelphia.

ASTM, 1980. - Standard practice for conducting acute toxicity tests with fishes, macroinvertebrates and amphibians. Report E 729-80. American Society for Testing and Materials, Philadelphia.

Avron M. 1986. - The osmotic components of halotolerant algae. Biochem. Sci.,11, 5-6.

Bailey S.A., Duggan I.C., Overdijk C.D.A.V., Johengen T.H., Reid D.F. \& Macisaac H.J. 2004. - Salinity tolerance of diapausing eggs of freshwater zooplankton. Freshwat. Biol., 49, 286-295.

Baird D.J., Barber I., Bradley M., Calow P. \& Soares A.M.V.M. 1989a. - The Daphnia bioassay: a critique. Hydrobiologia, 188/189, 403-406.

Baird D.J., Soares A.M.V.M., Girling A., Barber I., Bradley M.C. \& Calow P. 1989b. - The long-term maintenance of Daphnia magna Straus for use in ecotoxicity tests: problems and prospects. Pages 144-148 in Proceedings of the First European Conference on Ecotoxicology. Lokke H., Tyle H. \& Bro-Rasmussen F. (eds). Lyngby.

Barron S., Weber C., Marino R., Davidson E. \& Tomasky G. 2002. Effects of varying salinity on phytoplankton growth in a low - salinity coastal pond under two nutrient conditions. Biol. Bull., 203, 260-261.

Barry M.J., Tibby J., Tsitsilas A., Mason B., Kershaw P. \& Heijnis H. 2005. - A long term lake-salinity record and its relationships to Daphnia populations. Archiv Hydrobiol., 163, 1-23.

Boronat L., Miracle M.R. \& Armengol X. 2001. - Cladoceran assemblages in a mineralization gradient. Hydrobiologia, 442, 7588

Bos D.G., Cumming B.F., Watters C.E. \& Smol J.P. 1996. - The relationship between zooplankton, conductivity and lake-water ionic composition in 111 lakes from the Interior Plateau of British Columbia, Canada. Internat. J. Salt Lake Res., 5, 1-15.

Carvalho F., Guilhermino L., Ribeiro R., Gonçalves F. \& Soares A.M.V.M. 1995. - METIER (Modular Ecotoxicity Tests Incorporating Ecological Revelance). II. Ecotoxicity of poorly water-soluble compounds: concentration versus dose. Archiv. Environ. Contam. Toxicol., 29, 431-434.

Sánchez-Colomer M.G. 1996. - El uso del zooplankton como indicador biológico de la calidad del agua en 26 embalses españoles. Ingeniería Civil, 105, 55-64.

Cowgill U.M. \& Milazzo D.P. 1990. - The sensitivity of two cladocerans to water quality variables: salinity and hardness. Archiv Hydrobiol., 120, 185-196.

Do Hong L.C., Slooten K.B.V. \& Tarradellas J. 2004. - Tropical ecotoxicity testing with Ceriodaphnia cornuta. Environ. Toxicol., 19, 497-504.

EPA 2002. - Short-term methods for estimating the chronic toxicity of effluents and receiving waters to freshwater organisms. 4th edition. EPA-821-R-02-013.

Finney D. J. 1971. - Probit Analysis. Cambridge University Press, Cambridge, 333p.

Fisher M., Pick U. \& Zamir A. 1994. - A salt-induced 60-kilodalton plasma membrane protein plays a potential role in the extreme halotolerance of the alga Dunaliella. Plant Physiol., 106, 1359-1365. 
Hairston N.G., Kearns C.M., Demma L.P. \& Effler S.W. 2005. - Species-specific Daphnia phenotypes: a history and industrial pollution and pelagic ecosystem response. Ecology, 86, 1669-1678.

Hall C.J. \& Burns C.W. 2002. - Mortality and growth responses of Daphnia carinata to increases in temperature and salinity. Freshwat. Biol., 47, 451-458.

Hall C.J. \& Burns C.W. 2003. - Responses of crustacean zooplankton to seasonal and tidal salinity changes in the coastal Lake Waihola, New Zealand. New Zeal. J. Mar. Fresh. Res., 37, 31-43.

ISO 1996. - Water quality: determination of the inhibition of the mobility of Daphnia magna Straus (Cladocera, Crustacea) - Acute toxicity test. ISO International Standard 6341. International Organization for Standardization, Geneva.

ISO 2000. - Water quality: determination of long term toxicity of substances to Daphnia magna Straus (Cladocera, Crustacea). ISO International Standard 10706. International Organization for Standardization, Geneva.

Kefford B.J. 2000. - The effect of saline water disposal: implications for monitoring programs and management. Environ. Monit. Assess., 63, 313-327.

Kefford B.J., Palmer C.G., Pakhomova L. \& Nugegoda D. 2004. Comparing test systems to measure the salinity tolerance of freshwater invertebrates. Water SA, 30, 499-506.

Marques C.R., Abrantes N. \& Gonçalves F. 2004a. - Life-history traits of standard and autochthonous cladocerans: I. Acute and chronic effects of acetylsalicylic acid. Environ. Toxicol., 19, 518526.

Marques C.R., Abrantes N. \& Gonçalves F. 2004b. - Life-history traits of standard and autochthonous cladocerans: II. Acute and chronic effects of acetylsalicylic acid metabolites. Environ. Toxicol., 19, 527-540.

Meyer J.S., Ingersoll C.G., McDonald L.L. \& Boyce M.S. 1986. Estimating uncertainty in population growth rates: Jacknife vs. Bootstrap techniques. Ecology, 67, 1156-1166.

Nielsen D.L., Brock M.A., Rees G.N. \& Baldwin D.S. 2003. - Effects of increasing salinity on freshwater ecosystems in Australia. Austral. J. Botany, 51, 655-665.

OECD 1998. - Daphnia magna reproduction test. Test guideline 211.
Organization for the Economic Cooperation and Development, Paris.

OECD 2000. - Daphnia sp., acute immobilisation test. Revised proposal for updating guideline 202. Organization for the Economic Cooperation and Development, Paris.

Pereira J.L., Mendes C.D. \& Gonçalves F. in press - Short- and longterm responses of Daphnia spp. to propanil exposures in distinct food supply scenarios. Ecotox. Environ. Safe.

Petrusek A., Bastiansen F. \& Schwenk K. 2005. - European Daphnia Species (EDS) - Taxonomic and genetic keys (Build 2006-01-12 beta). CD-ROM distributed by the authors. Department of Ecology and Evolution, J. W. Goethe-University, Frankfurt am Main, Germany \& Department of Ecology, Charles University, Prague, Czech Republic.

Rokneddine A. \& Chentoufi M. 2004. - Study of salinity and temperature tolerance limits regarding four crustacean species in a temporary salt water swamp (Lake Zima, Morocco). Animal Biol., 54 , 237-253.

Schallenberg M., Hall C.J. \& Burns C.W. 2003. - Consequences of climate-induced salinity increases on zooplankton abundance and diversity in coastal lakes. Mar. Ecol. - Prog. Ser., 251, 181-189.

Schuytema G.S., Nebeker A.V. \& Stutzman T.W. 1997. - Salinity tolerance of Daphnia magna and potential use for estuarine sediment toxicity tests. Archiv. Environ. Contam. Toxicol., 33, 194198.

Semsari S. \& Haït-Amar A. 2001. - Effets de la salinité et de la dureté de l'eau sur la toxicité des métaux vis-à-vis de Daphnia magna Straus. Ann. Limnol. - Internat. J. Limnol., 37, 75-83.

Soares A.M.V.M., Baird D.J. \& Calow P. 1992. - Interclonal variation in the performance of Daphnia magna Straus in chronic bioassays. Environ. Toxicol. Chem., 11, 1477-1483.

Tackx M.L.M., De Pauw N., Mieghem R.V., Azémar F., Hannouti A., Van Damme S., Fiers F., Daro N. \& Meire P. 2004. - Zooplankton in the Schelde estuary, Belgium and the Netherlands. Spatial and temporal patterns. J. Plankton Res., 26, 133-141.

Teschner M. 1995. - Effects of salinity on the life history and fitness of Daphnia magna: variability within and between populations. Hydrobiol., 307, 33-41. 